Kohl: a Journal for Body and Gender Research

Vol. 5, No. 2 (Summer 2019)

\title{
Neoliberal Consciousness and the Emotional Labor of Coping: A Conversation Between Friends
}

Nadine El-Nabli and Amira Elwakil

This conversation is part of an ongoing series of our collective reflections on labor, neoliberal consciousness, and coping/surviving. In sharing this as a transcribed conversation, we want to expand the space in which we talk about these struggles, and do so in a format that feels faithful to how we use conversation as care in our friendship.

As part of her paid work, Nadine is a course instructor at the Netherlands-Flemish Institute in Cairo, where she designs and teaches courses on gender in contemporary Egypt as part of a semester abroad Middle East Studies program for students from the Netherlands and Belgium. Amira's paid work is with adults (primarily women) from migrant communities in London, teaching English for Speakers of Other Languages following a radical pedagogy. In addition to teaching, she campaigns alongside the students she works with on issues that matter to them. 


\section{Labor, emotionality, and emotional labor}

Nadine: I feel that emotional labor is part of everything in my life. There's not a state in which emotional labor and emotionality of some sort aren't involved. It's inevitable because we are always carrying our emotions with us wherever we go, in whatever we do, and with whomever we engage with. And sometimes we are consciously making decisions to exert energy and effort into using this emotional labor in a certain way. And other times we find ourselves having to do it or this expectation is placed upon us to do it more than on other people, which is obviously very gendered and present in so many of my relationships. But I like to do it. And yet I can't do it all the time. So it's extremely difficult to navigate. Every relationship is work. I have to use emotional labor in my job but I also have to use emotional labor in everything that is not my "job." I guess that just being alive is laborious.

Amira: I'm reflecting. So are you then saying that labor permeates everything? Is there labor in everything?

$\mathrm{N}$ : Yes, I think so. There is even labor involved in being alone. There's always this constant effort to navigate living in the world. And I find that for any relationship and any job, there are certain emotions that you're supposed to perform and that are obviously gendered. So living and surviving is laborious. Emotional labor is exerted to survive but also to navigate all our relationships. There are things that I think are necessary, but it's also inherently upholding the structure. If emotional labor were to cease to exist or were disrupted, then the system itself wouldn't be able to operate. At the same time, I feel like if it is recognized, acknowledged, respected, valued, and meaningfully incorporated in how we understand living in all its different ways, then it can actually become a resistance to these structures. Feminists have just started developing and creating the space and language to understand the multifaceted nature of emotional labor, how it affects our lives, and how we can use it in a way that's meaningful and also political.

A: I very much agree with that. I actually like how you talk about emotional labor in general, beyond this conversation, and how you often say "I wish this was my job. I want to care for all the people that I love." And this is effort. It's work. It's time. If you have a formalized job alongside doing that, you won't have enough capacity to do as much of it as you'd like to. And I think your reflections on that have really helped me understand a lot of things for myself about the different forms of invisible or invisibilized (to quote you) labor that I engage in - with emotional labor being but one example - and my wanting to be there, in an emotional sense, for all the people I care about. This also got me thinking a bit now about the neoliberal context we live in and how it violently enforces a dismantling of collectivity, where there is no "being there" for people we love actually. So it's: "let's zoom in on the individual who has full responsibility for their welfare. The onus is on them to find a job that pays them well. And that person has to look after themselves emotionally as they cope with labor in all its forms, many of which we won't recognise." I feel that individualization of existence is pretty much at the heart of the neoliberal project.

$\mathrm{N}$ : Any presence of emotions or emotionality as part of our labor structures is feminized, and in turn undervalued. In fact, this emotionality is only acceptable in certain spaces, in certain professions, performed by certain people. But otherwise, we should not be emotional. Consciously engaging emotions 
within our traditional labor structures is seen as negative and "unproductive." And I think there are many reasons for this, one of which is this romanticization of emotional labor - even terming it "labor" is often controversial. Caring is supposedly something you can't "put a price on" and should transcend everything because it's rooted in romanticized ideas around love. And of course these romanticized ideas are extremely gendered, whether in the workplace or in families and homes.

A: I actually struggle with this so much. In my classes, whenever we explore the theme "work," I often get some students strongly arguing that what they do as mothers and unpaid carers should not be classified as work. Instead, they stress on the very transcendence you're talking about in what they do in their roles, and how it should not be "tainted" by our traditional labor structures. I don't personally agree with this, but I feel we need to make room for this narrative of transcendence when it's argued for by some of the people at the forefront of it, especially when I feel their agency and choices in this context are often dismissed under the banner of false consciousness. We do end up discussing the need for recognition, though, and there's unanimous agreement on that.

$\mathrm{N}$ : And I think that there is a difference between recognizing and formalizing or bureaucratizing. I wouldn't necessarily want emotional labor to be sucked into the existing labor structures per se. I wouldn't want for there to be a contract or a specific hourly wage. I don't envision it like that. But my hope is to try and where emotional labor is not just acknowledged, but also accompanied by some form of security for those practicing this labor, so that this security isn't dependent on gendered partnerships. I personally wish I could spend my time taking care of myself and my communities, but the question I am always confronted with is: how do I survive?

\section{Teaching as emotional labor}

A: Yeah, and there is also the question of how emotional labor in general is distributed. I feel this immediately makes us hone in on the material consequences all of this has on our well-being, right?

$\mathrm{N}$ : I think questions of mental health are inherently connected to this question about both emotional and material survival. As a woman I am expected to do emotional labor in both my personal and professional relationships, and since this isn't recognized as labor, I have to do all these additional tasks that are considered "real work" that will be monetarily compensated. So if I were to recognize the time and energy I put in doing emotional labor in my life, it becomes harder to participate fully in traditional labor structures because I am exhausted. So if a person struggles to, or is unwilling to take on these multiple burdens and layers of labor, their behavior often gets pathologized. Since they are deemed to not be "a productive member of society" in the neoliberal sense, they must have a problem that needs to be "fixed."

A: I wholeheartedly agree with what you're saying about exhaustion; I find that exhaustion is a constant in my life, and I sometimes catch myself thinking of it vis-a-vis "productivity," which I find deeply unsettling. Exhaustion is immediately pathologized: little attempts are made to understand where it comes from and 
see how deeply political it is and can be. I do find all of this very difficult to navigate, though, because we want to acknowledge the existence of mental health issues as issues in and of themselves, but also see their very intimate interconnectedness to the structures we exist in and how they impact our mental health. I fear there's a risk of polarization: you either have a medical condition and therefore you're unwell, or you are experiencing violence through the structures you live in and therefore you're unwell. There's an abhorrent depoliticization of mental health struggles, but possibly also a hyperpoliticization of them that hinders us from understanding our states and our bodies. I want to be able to do both, to understand the political, but also how my depression, that is very real and very painful, operates on a physiological level. I actually want to reflect a bit on myself here and my work as a teacher in relation to what we're saying and the neoliberal context we're in. There's a lot of emotional labor involved in being a teacher, and not just in listening to students. A student recently told me how appreciative she is that I'm "always smiling" and how that's conducive to her learning. I don't believe she meant to put pressure on me to perform in that way, but it made me reflect on my "responsibilities" as a teacher beyond the material I'm exploring with the class. A lot of teaching in a radical and participatory context involves fostering an environment that allows for so many possibilities in terms of conversation to take place. In this context, there are often tears that are difficult to predict, especially given that we are always exploring issues from our lives that inevitably carry varying degrees of pain. You become hyperaware of the violence everyone is experiencing simultaneously, and so, when there's room for us to name the problem, the experience can be full of immense emotion, which can be cathartic but also incredibly painful. So there's emotional labor in the classroom and in planning, but I also often leave work feeling distraught at the violence and pain experienced and shared. There's helplessness and hopelessness experienced, and it lives beyond the walls of the classroom. What do I do with all this pain, individual and collective? And of course there's also the politics of working in a precarious sector that is highly feminized, and that lies at the center of the many racist and anti-migrant narratives and policies that exist. It's just this very volatile political context. I can't separate my well-being from that. It has a very direct impact on it. And that's just formalized work, I haven't even gone into other contexts in my life.

$\mathrm{N}$ : I completely agree about the emotional labor of teaching. You want to be creating the space where people can speak, be critical and feel safe all at the same time. What you were saying was getting me thinking about my teaching context which is very different to yours. In addition to this emotional labor of being a teacher more broadly, I'm teaching students who are predominantly white and coming from Western universities. And so I feel a specific kind of responsibility when I'm in the room to challenge and disrupt their thinking around certain issues and I want to make sure they understand how serious and violent the things we're talking about are while at the same time making sure they don't leave the room feeling hopeless - even though I myself feel hopeless most of the time. And I expect them to reflect on their complicity and their roles in these structures. I always leave my classes questioning: Did I do enough to make sure that they are being critical about this? Do they have the tools to understand these structures? Do they understand their responsibility in this? And most crucially, are they okay? And I always have this sense of urgency that I wish I had more time to explain and discuss with them but at the same time I'm so exhausted. I can't imagine teaching every single hour of the week like that. I don't even know how I would survive that. I need a whole day to process one class. 
A: I can't imagine myself doing that either! It's also tiring that there is no recognition, right? There's no recognition of the emotional labor involved and there's definitely no recognition of the impact this has on our mental health. What am I to do with this overwhelming sense of hopelessness that my students talk about and that I feel? This is at the heart of the depression I experience, this hopelessness, which is so firmly confirmed by so many examples on a daily basis. When you are prone to depression, and those are your reference points, it literally throws you into an abyss. And I keep wondering: how do we look after ourselves?

\section{Coping, guilt, and the co-optation of self-care}

$\mathrm{N}$ : I know I try to avoid exposure to too many stimuli because it's everywhere. It's everything. But I don't know if this is a sustainable and "helpful" strategy for me, to be honest.

A: I think acknowledging that there is too much stimulation in the world, and minimizing exposure to it is a coping strategy I use too. But it does come at the expense of so much; managing stimulation can often mean isolating myself from people I love. Going back to the point you mentioned earlier about the emotional labor that comes with just existing, I do end up prioritizing the labor involved in looking after myself, the labor of coping, which I guess is emotional labor, over the emotional labor involved in being there for people I love, who are also struggling. I can't do all of these things at the same time, and it seems like I can't do them most of the time when I feel that I'm spending my life treading water and trying not to fall into that abyss; there is no "neutral." So then I end up in this position where I am prioritizing certain forms of labor and it is just to survive - I'm not talking about anything even remotely leisurely. This is literally to cope and to survive.

$\mathrm{N}$ : As you're speaking I'm thinking about how I'm coping. I'm very selective about the ways in which I engage with the world. But I feel really guilty about this at the same time because I have the privilege to try to avoid and disappear. This is reminding me of Dina Makram-Ebeid's Facebook post ${ }^{1}$ about the feeling of wanting to disappear when in Cairo in order to survive, and the obvious privilege and guilt of being able to disappear at all. But at the same time I have not figured out another way to survive yet that doesn't involve minimizing or being selective about how I engage with the world. Maybe I never will.

A: Yeah. Guilt underpins a lot of what l'm saying, actually. And it's a difficult one because I want to engage with these feelings of guilt; they are important and they're linked to a very political question that is integral to us undoing damage that's being done onto us collectively and individually, and that includes damage and violence that we are complicit in. But at the same time I worry that the instilment of this sense of guilt is also a neoliberal project. It's a strange dichotomy to exist in.

1 Dina Makram-Ebeid (Facebook account), March 18 2017:

https://www.facebook.com/dina.makramebeid/posts/10100788279339051 
Privilege is the main source of guilt, I suppose: being able to engage in these conversations at all, having the language to name these things, being able to I access that language from privileged locations, having the spaces and the time to look after myself and access services that help me survive, having safety nets... There is also guilt around what I said earlier about the prioritization I end up doing of myself over others, which is in itself very neoliberal, I feel. I'm often stuck in this thought process of "I'm perpetuating the very things about this system that led me to this state I'm in. I'm using its essential tenets to look after myself." This carries a lot of anxiety with it, and reminds me about the co-optation of self-care by neoliberalism that we often talk about.

$\mathrm{N}$ : I think the question of the co-optation of self-care ties into what you were saying about the struggle and labor to cope. Self-care is being co-opted within neoliberalism in a way that very clearly intends to perpetuate the structure. Products and services that are supposedly for your well-being are really about rebranding consumerism culture and continuing to be "productive" in the neoliberal sense. It's self-care in service of neoliberal capitalism. And you're left with this struggle of how to actually do self-care while not also feeding into this narrative and these structures.

A: That's exactly how I think of it. In London there is this overwhelming presence of self-care consumerism that you're constantly exposed to, and that includes the rise of "wellness culture." These are often packaged in a way that is in service of neoliberal capitalism as you say. "Unwind after a long day at work," "Get your energy boost on your way to work," but there is no challenging of work itself.

I often find myself resisting it so much, and then obviously this has a bad impact on me because some of the things that are sadly consumable can sometimes help me. So it's a difficult question: how do I avoid being a participant in self-care consumerism and resist it while making sure I engage in self-care?

\section{Searching for alternative labor structures}

$\mathrm{N}$ : Again these are the constant negotiations and struggles that come with figuring out what it means to take care of yourself. And again it brings up all these layers of guilt related to self-care. You feel guilty about having access or time to do self-care, and you feel guilty for potentially consuming these products or services. And then you feel guilty for feeling guilty, because being able to feel guilty is a privilege.

I think that's also another aspect to the labor of coping; there is the labor involved in doing practices to take care of yourself, which requires effort and time. But there is also the labor of navigating the politics and negotiations of trying to take care of yourself without perpetuating the things you are trying to resist and that contribute to your mental health struggles in the first place. It is also about allowing yourself to take care of yourself when you would rather be resisting and fighting. Again, it's exhausting.

A: Immensely so. So what then are alternative ways to doing all of this?

$\mathrm{N}$ : We haven't really touched upon structures of care or communities of care, which are an integral part of alternative labor structures. Any attempt to challenge our current labor structures and create alternative 
ones requires a new way of thinking around how we organize communities and how we distribute care, security, recognition, rights, and duties. I think it's crucial to try to find alternative communities of care that are neither based on ideas around the nuclear family nor in the pursuit of creating a new family that is rooted in heteronormative structures. But I haven't managed to find an answer to what these communities could realistically and sustainably look like. I find so much value, support, and care in friendships, but even those feel insecure because of the fact that the structures we live in don't support the sustainability or security of these relationships.

A: I agree. Having elements of the communities of care you're imagining here in my life has been integral to my ability to cope, be it in friendships, partnerships, or formalized work contexts. l'd actually like to go back to my current formalized work to supplement some of what we're saying here. I'm just lucky to be in a context where my colleagues are aligned with me on many fronts vis-a-vis these issues. We often have very frank conversations about how we can better support each other and how that can be part of what we do, and we center emotionality in our teaching and beyond. Also, the premise of our approach is that the classroom is political in various ways, and that a lot can be brought into and taken out of that space, which allows for organizing and action alongside our students. Maybe there is something about the collective nature of that that helps. I think it's really rare but it is possible to have small groups of people in a traditional employment context where there is that support. I wonder if some jobs and employment contexts tend to attract certain people by their very nature and, therefore, bring together people that could foster an environment where they can collaboratively create communities of care with those tenets you mentioned. So I think that in itself is a resistance to the neoliberal idea that every individual is responsible for $X$ number of tasks and this is what they're accountable for. Emotional and other invisibilized labor are integral parts of working, and making this as explicit as possible is a good first step when looking at the currently formalized labor structures we have. I think there is room for that.

$\mathrm{N}$ : And this ties into the questions we were bringing up in the beginning as well. How do you survive when your time is invested in emotional labor that isn't formally recognized? And how do you survive when you need to take care of yourself, when that self-care involves not doing or minimizing work that is waged? How do you survive in a material sense? I do think it is possible, as you're saying, to create alternative, collective approaches to how you do work. There aren't a lot of places willing to do that, of course, but maybe we can think of things that have worked for us or not worked for us in places we've done waged labor.

A: It definitely helps to work in a context where there is a constant challenging of hierarchies, and where your productivity and your wage, and therefore, your survival in a capitalist context, are not intimately interlinked. What also helps is feeling trusted that I will do the work that needs to be done, but also having room to communicate struggles with doing that work should they come up. I suppose it's about what is referred to as "work culture," so it's a collective effort, where care as work is shared. Radical labor structures definitely involve more emotional labor. And they definitely involve recognition of the emotional labor involved in what we do, day in, day out. 